\title{
A Risk Analysis of Adjusted Gross Revenue-Lite on Beef Farms
}

\author{
Jeffery R. Williams, Andrew T. Saffert, G. Art Barnaby, \\ Richard V. Llewelyn, and Michael R. Langemeier
}

\begin{abstract}
This study evaluates the Adjusted Gross Revenue-Lite (AGR-Lite) whole-farm adjusted gross revenue insurance program on net farm income risk using panel data from 49 southeast Kansas beef farms. On average for the group, but not each individual farm, AGR-Lite reduces the mean and standard deviation of net farm income, raises the average minimum, and lowers the average maximum observations of the net income distribution. Thirty-four farms (69\%) received at least one indemnity payment. Stochastic efficiency with respect to a function reveals that AGR-Lite is preferred by 18 of the farm managers (37\%) when an upper bound on the risk-aversion coefficient is used.
\end{abstract}

Key Words: AGR-Lite, beef farms, risk analysis, whole-farm revenue insurance

JEL Classifications: Q12, Q18

Crop and livestock insurance transfers production risk to insurance providers who are reinsured by the Risk Management Agency (RMA). This study examines the effectiveness of a relatively new whole-farm revenue insurance product, AGR-Lite, on net farm income risk for a group of beef farms using farm-level data. RMA deemed the AGR-Lite-type coverage was a necessary addition to their portfolio of insurance products because livestock and many minor fruit and vegetable crops had no or only limited coverage provided by traditional insurance products.

Jeffery R. Williams is a professor, Andrew T. Saffert is a former research assistant, G. Art Barnaby is a professor, and Richard V. Llewelyn is an extension assistant, Department of Agricultural Economics, Kansas State University, Manhattan, Kansas. Michael R. Langemeier is a professor, Department of Agricultural Economics, Purdue University, West Lafayette, Indiana.

We thank two anonymous reviewers and the editor for their helpful comments.
The Agricultural Risk Protection Act (ARPA) of 2000 allowed the development of federally reinsured livestock products. Before the enactment of ARPA, livestock remained a sector effectively excluded from RMA insurance programs. Livestock Risk Protection (LRP), a federally reinsured livestock product for swine, fed cattle, and feeder cattle, was approved by RMA in 2001. LRP is designed to protect producers against market prices falling below some predetermined coverage price. Livestock Gross Margin (LGM) insurance became available in 2006 for cattle and in 2007 for swine and dairy. LGM protects gross margin, which is livestock market value minus feed costs. Producers receive indemnities equal to the difference between actual gross margin and guaranteed gross margin if positive. RMA has limited the aggregate national maximum liability (effectively the maximum number of contracts) for the livestock products and this limits the number of producers who may buy coverage. Many of the contracts also limit the 
size of an operation that may buy effective coverage, whereas crop insurance has no limits on the number or size of operations that may purchase coverage.

Adjusted gross revenue (AGR) became the first revenue product to insure a percentage of average gross revenue for the entire farm in 2001. AGR provides coverage under one policy for multiple agricultural commodities. A further innovation, Adjusted Gross RevenueLite (AGR-Lite), was introduced in 2003. AGR-Lite is whole-farm revenue insurance, which provides protection against low revenue resulting from natural disasters causing production losses and commodity market fluctuations that affect revenue. Most farm-raised crops, animals, and animal products are eligible for protection.

AGR-Lite differs from AGR in several ways with the most notable being that there is no limitation on the percentage amount of receipts from animals or animal products for AGR-Lite. AGR limits the allowable farm income (AFI) from livestock to $35 \%$ of total allowable farm income. This makes it much more useful for livestock producers, the focus of this study. Other differences include a maximum policy liability of $\$ 1$ million for AGR-Lite, whereas maximum policy liability is \$6.5 million for AGR, and commodities with small revenues can be grouped to determine diversification credits for AGR-Lite (not allowed for AGR).

AGR-Lite may be used as a standalone product or as an umbrella (wraparound) policy allowing producers to use AGR-Lite in conjunction with alternative insurance policies, excluding AGR. Limitations of AGR-Lite specify that a qualifying person can generate no more than $50 \%$ of their total revenue from commodities purchased for resale. It is important to note the resale limitation does not apply to commodities purchased for further growth such as stockers, cattle that are backgrounded, and fed cattle. This insurance product, although complicated, has a more simplified design than AGR but still provides revenue protection for all crop and livestock enterprises.

Exploring the use of crop insurance as a risk management instrument and its significance in the agricultural industry has been widely researched. ${ }^{1}$ Yield-based designs have been studied by Atwood, Watts, and Baquet (1996), Carriker et al. (1991), Miranda (1991), Patrick and Rao (1989), Wang et al. (1998), and Williams et al. (1993). Analysis of various revenue designs includes work by Dismukes and Coble (2006), Dismukes and Durst (2006), Feuz (2009), Llewelyn et al. (2003), Miller, Coble, and Barnett (2000), Mishra and Goodwin (2006), Richardson, Smith, and Knutson (2001), Schnitkey, Sherrick, and Irwin (2003), Schumann et al. (2001), Stokes, Nayda, and English (1997), and Turvey (2010).

Barham et al. (2011) used Stochastic Efficiency with Respect to a Function (SERF) analysis to evaluate strategies for managing cotton revenue risk on irrigated cotton farms in Texas. They found crop insurance strategies to mitigate risk were preferred at lower levels of irrigation with the use of crop insurance declining as irrigation levels increased. This analysis did not include revenue from livestock.

Schnitkey, Sherrick, and Irwin (2003) used net costs, values-at-risk (VaRs), and certaintyequivalent returns (CERs) to evaluate alternative crop insurance mechanisms including actual production history (APH), revenue assurance (RA) with base-price option (RABp), RA with harvest-price option (RAHp), group risk plan (GRP), and group risk income protection (GRIP). Mishra and Goodwin (2006) used cash grain farm data from the 1998 Agricultural

${ }^{1}$ Beginning in 2011, the Risk Management Agency (RMA) renamed many of the crop insurance products with only minimal changes made to them. MultiplePeril Crop Insurance (MPCI) was renamed Yield Protection insurance (YP) in the Common Crop Insurance Policy (CCIP) and is the longest running insurance design, providing protection for individual commodities. Income Protection (IP) and Revenue Assurance without the harvest price (RA) were combined into a single product with minimal changes and renamed Revenue Protection with the Harvest Price Excluded (RP-HPE). RMA also combined Crop Revenue Coverage (CRC) and Revenue Assurance with the harvest price option included (RA-HP) with nominal changes and renamed the product Revenue Protection (RP). The Group Risk Products were not renamed. The literature generally refers to these products by their previous product names before 2011 . 
Resource Management Study and a logit model to determine factors that affect purchase of revenue insurance. Factors affecting the decision included age, education, production and marketing contracts, gross farm sales, land tenure, debt-to-asset ratio, returns to revenue insurance, and government program participation.

Preferences and purchase decisions for hypothetical livestock price insurance products were evaluated for beef producers in Louisiana using survey data and conjoint analysis (Fields and Gillespie, 2008). Producers who expressed greater preference for purchasing these products were more risk-averse and preferred these products when prices were expected to vary in the near future. The hypothetical products included in the analysis were price insurance only and did not include whole-farm revenue insurance like AGR-Lite.

Limited research has been conducted on whole-farm revenue insurance options. Stokes, Nayda, and English (1997) indicate that for a representative Tennessee farm, gross revenue assurance on a whole-farm basis is less expensive than a weighted average of assurance prices on an individual-crop basis because of price and yield covariability between crops produced. Richardson, Smith, and Knutson (2001) examined whole-farm revenue plans for representative farms using simulated income data. Schumann et al. (2001) explored alternative safety net programs, including Catastrophic (CAT) coverage, multi-peril crop insurance (MPCI), Whole-Farm Revenue Program (WFRP), and Farm and Ranch Risk Management (FARRM) accounts. Llewelyn et al. (2003) also explored the impact of FARRM accounts on net income and variability.

Dismukes and Durst (2006) report that an important issue in the design of whole-farm revenue insurance is the complexity of factors that determine farm income and how those factors vary across farms and time. They believe whole-farm revenue insurance is difficult to administer. Dismukes and Coble (2006, p. 26) also state that "How well a farm's historical income indicates expected income in the insurance year is also critical." Changes to the farm that affect income are a function of the amount of land and how the land is used and not only production and price variability. They go on to note that complex rules, which are included in this study, have been developed for measuring revenue and validating losses under AGR-Lite. Turvey (2010) examined the effect of whole-farm insurance on farm portfolio choice with math programming models for a representative Manitoba crop farm. The study reports that farm managers will alter farm plans significantly in response to the type of insurance and take on production risks they would not otherwise take.

Little work has been completed that examines the effectiveness of AGR-Lite for reducing risk. Feuz (2009) compared cash pricing to using futures, options, or AGR-Lite for managing risk for a cow-calf producer, finding that AGR-Lite was not an effective policy for cowcalf producers. The analysis was based on a cow-calf enterprise budget using simulation analysis but did not consider whole-farm data from tax returns as AGR-Lite requires.

This research is unique because it uses actual detailed farm data to reproduce the information needed to use AGR-Lite. Dismukes and Durst (2006, p. 1) state that, "there is no broad program of income support or insurance for livestock." Therefore, this research concentrates on beef farms because AGR- Lite potentially can provide more risk protection to beef farms than has been available for them previously.

The impact of participation in AGR-Lite is evaluated for southeast Kansas beef farms on net farm income (NFI) variability. Kansas Farm Management Association (KFMA) data are used to compile 18 years (1993-2010) of continuous farm-level data, which is then used to evaluate participation in AGR-Lite (Langemeier, 2010). These farms obtained more than $50 \%$ of their average total income from beef production over the 18 years.

According to census data for 2007, Kansas' top six commodities (by production value) account for $\$ 14.3$ billion or $99 \%$ of the state's agricultural production (U.S. Department of Agriculture [USDA], 2009). However, only one of these commodities is widely insured: grains, with $\$ 4.5$ billion, accounting for $31.6 \%$ of Kansas' agricultural production. The commodities that 
historically are uninsured in the top six (by production value) are cattle and calves, $\$ 8.5$ billion; hogs, $\$ 506.4$ million; milk and other dairy, \$376.5 million; hay and other production, \$253.9 million; and nursery and greenhouse, $\$ 77.0$ million. These historically uninsured commodities account for $\$ 9.8$ billion, or over $68 \%$ of agricultural production in Kansas. These statistics further substantiate the need for analysis of AGR-Lite.

\section{AGR-Lite Overview}

AGR-Lite is the first Federal Crop Insurance Corporation (FCIC) program to provide coverage for crops, animals, and other previously uninsurable commodities under one product by insuring whole-farm revenue. Producers must file an intended agricultural commodity report, to be submitted at the beginning of each eligible insurance year detailing the commodity, expected acreage, yield, expected value, and total value. Qualifying farms must also submit a minimum of five years of continuous, verifiable tax records for the same entity, preferably Schedule F 1040 filings or equivalent tax forms to document historical revenue and expenses and, before January 31 of the insurance year (March 15 for new applications), must file beginning inventory for that insurance year, including crops in storage and accounts payable and receivable. These records are then used to calculate the critical values, as described in further detail subsequently.

The revenue guarantee is determined using the approved AGR, which is based on the lesser of the five-year average or indexed AGR (whichever is applicable) from tax returns or the expected farm income for the current insurance year. Expected farm income is derived from the intended agricultural commodity report. The revenue guarantee level or lossinception point is equal to the approved AGR multiplied by the selected coverage level. When a producer realizes a shortfall in gross revenue below the guarantee level, an indemnity is paid on the difference based on the producer's selected payment rate percentage.

AGR-Lite includes procedures for indexing and factoring to account for expansion or contraction in farm size. With the ability of farm managers to shift income from year to year, accrual adjustments are used during the claim submission process to ensure income is appropriately assigned to the year in which it is produced. After the necessary adjustments, producers are eligible to receive an indemnity when adjusted gross revenue to count (AGRC) for the current insurance year falls below the guaranteed level. This policy is described in USDA (2008, 2010). Procedures used to construct the critical values are described in greater detail in an appendix in Williams et al. (2013). Equation numbers beginning with the letter included in parentheses in the "Data and Methodology" section refer to equations in the detailed appendix.

\section{AGR-Lite Critical Values}

AFI is the income measure used for establishing the AGR-Lite guarantee (liability) and includes, by definition, any income generated from the production of insurable commodities less any added value resulting from postproduction activities. The calculation of AFI includes items 1e, 2b, 3b, 5a, 5c, and 8b from Schedule F. Ineligible income sources excluded from AFI calculations are federal or state fuel tax credits and refunds, cooperative dividends, custom hire (machine work), agricultural program payments, Farm Service Agency (FSA) loans, Noninsured Crop Disaster Assistance Program (NAP) payments, ad hoc disaster assistance, and crop insurance payments as well as a few other minor categories of income. AGR-Lite requires farm managers to maintain accurate and comprehensive expense records. Although AGR-Lite guarantees gross income, expense records are maintained to detect downsizing farms and monitor for the presence of moral hazard. Expense records are analyzed as part of the claim submission process, and the insured's guarantee is subject to adjustments. Allowable Expense (AE) includes Schedule F expenses directly associated with the production of insurable commodities (lines 10-14, 16-20, 22, 25-28, and 30-32). Expenses that do not directly influence production or gross income are not included. 
The AGR-Lite program is complex and thus requires very detailed data from the insured. This complexity may be at least part of the reason that relatively few policies have been sold in Kansas or nationally despite the potential benefit of insuring against production risks and basis risks, which are not mitigated by other insurance products for livestock that only cover price risk. This study evaluates the effect of AGR-Lite on risk reduction and net farm income for actual beef farms in southeast Kansas, seeking to determine if the policy may have benefits for producers despite the complexity involved with using it.

\section{Data and Methodology}

A panel data set for 49 southeast Kansas beef farms for the period of 1993-2010 is used to evaluate the impact of AGR-Lite on NFI variability. These data are obtained from the KFMA data set, which was expanded in 1993 with additional variables including those required for this analysis (Langemeier, 2010).

The KFMA data are used to calculate the income and expense values necessary for AGRLite, including: AFI, AE, Change in Prepaid Expenses $(\triangle \mathrm{PE})$, Change in Accounts Receivable $(\Delta \mathrm{AR})$, Change in Inventories $(\Delta \mathrm{IN})$, and
NFI. These values are determined for each farm for every year from 1993 through 2010. Using these variables, distributions for indemnity payments, AFI, AGRC, and NFI with and without participation in the AGR-Lite program for the years 1999-2010 are generated. To model the AGR-Lite program, two data sets are required. The first data set, including years 1993-2010, is required to compile the necessary information to generate five-year Adjusted Gross Revenue Average (AGRA) and AE from equations A2 and A8. A second subset of the data, from 1999-2010, is assembled to compute accrual adjustments $(\Delta \mathrm{AR}, \Delta \mathrm{IN}$, and $\Delta \mathrm{PE})$ and NFI.

All farms were screened to ensure there were no negative values for AFI, which is a gross income measure, AE, Prepaid Expenses (PE), and Accounts Receivable (AR) and that none exceeded the maximum liability coverage allowed. The 49 farms have, on average, 696 acres of cropland and 1847 acres of pasture. Figure 1 illustrates the average values of AFI, NFI, and Value of Farm Production (VFP) for the 49 farms remaining after screening for data errors from 1993 through 2010. One of the critical variables in the AGR-Lite policy is adjusted gross revenue to count (AGRC). Its value is reported in Figure 1 beginning in 1999

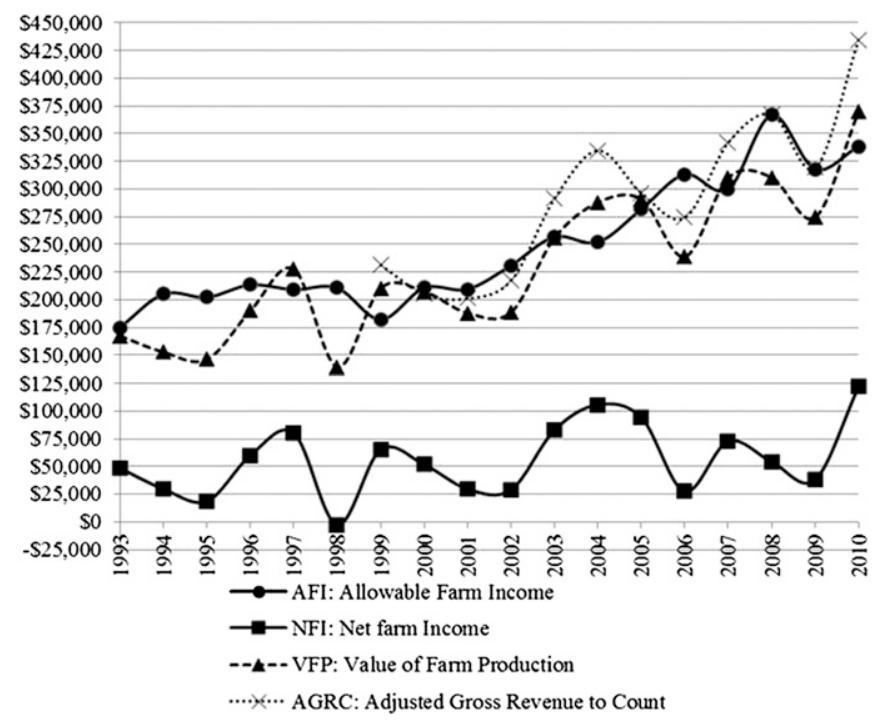

Figure 1. Trend in Income Variables for 49 Southeast Kansas Beef Farms from 1993 through 2010 
as a result of the structure of the policy and availability of continuous data beginning in 1993. The policy requires five years of data ending two years before the insurance year. Although the KFMA data do not contain individual tax records, annual farm-level data from 1993-2010 is used to reproduce the tax schedule information necessary to evaluate AGRLite using NFI distributions with and without participation in the AGR-Lite program. The following sections provide further explanations of calculation procedures.

\section{Allowable Income}

A five-year average of AFI is calculated for each insurance year over the study period. The years 1993-1997 are used to determine the five-year base for the insurance year 1999, as required by the policy. For year 2000, the fiveyear average uses years 1994-1998. For each subsequent year, the five-year average shifts forward one year. Thus, an individual enrolling in 2010 would derive AFI and Adjusted Gross Revenue Average (AGRA) using base years 2004-2008. AGRA is computed based on historical records and remains the same, unless indexing adjustments are required, as described subsequently.

\section{Indexing}

Indexing is used to ensure effective coverage. At each annual enrollment, calculations are performed to monitor the farm's growth to detect whether adjustments are warranted. Eligibility for indexing occurs when AFI from either of the two most recent years in the base period in the five-year average and the Expected Income (EI) reported on the annual farm report required by AGR-Lite exceed the fiveyear average. As part of the enrollment process, farm managers submit annual farm reports, which indicate the intended commodities to be produced, anticipated production (based on average yield), and a forecasted income from each commodity (based on current market value or contracted value).

When conditions for indexing are satisfied (as defined previously), a series of calculations are performed to reveal the extent to which the farm guarantee is adjusted (equations A3-A5) to prevent "under- and overinsuring." Using indexing procedures, the Approved Adjusted Gross Revenue (AAGR) is established. AAGR is the value used in establishing contract liability and calculating the insurance premium.

\section{Coverage Levels and Payment Rates}

AGR-Lite offers three Coverage Levels (CLs) $(65 \%, 75 \%$, and $80 \%)$ with indemnity Payment Rates (PR) of $75 \%$ or $90 \%$ of AGR. The coverage level is the level of AAGR at which indemnity payments begin. Multiplying AAGR by the CL provides the loss-inception rate. The payment rate determines how much the producer will be paid for each dollar below the loss inception point. A producer selects one amount of coverage that will cover all commodities. For each combination of CL and PR, the policy caps maximum liability (equation A6). AGRLite liability (AGRL) is calculated by multiplying AAGR by the selected CL and PR or, alternatively, the loss-inception point multiplied by PR. These maximum liabilities represent the maximum AAGR an individual may generate and still trigger an indemnity for AGR-Lite. USDA (2010) provides a summary of coverage levels, payment rates, minimum number of commodities, and maximum annual income limitations for the current AGR-Lite policy.

\section{Expense Indexing and/or Factoring}

Farm managers must maintain accurate records of expense activity throughout the insurance year. Although AEs have no impact on determining the initial guarantee, because the contract guarantees gross rather than net income, expense records are used at various phases of the insurance process. Furthermore, AE accounting works to reduce the incidence of individuals engaging in moral hazard (equation A7). In some instances, AE will ultimately result in adjustments to the guarantee level. Similar to AFI, a base period is established to derive a five-year Allowable Expense Average (AEA). Consistent with AFI, the AE base period 
includes five years beginning two years before the insurance year (equation A8).

Approved Allowable Expenses (AAE), for the current insurance year, are dependent on procedures applied to AFI (equations A9A12). When conditions for income indexing are satisfied (when two of the most recent years in the base period exceed the five-year average), an expense indexing trend factor is calculated (using a similar procedure discussed previously for AFI). When income indexing occurs, factoring up ensures a proportional adjustment in expenses and determines Factored Allowable Expenses (FAE) for the current insurance year. Alternatively, where income indexing does not occur, expenses may be "factored down" proportionally to capture a reduction in farm size. Factoring down recognizes that as AFI declines, AE may also be less. Factoring down will occur when AAGR is less than AGRA.

\section{Indemnity Calculation}

An AGR-Lite indemnity is calculated using the following procedure. Production Expense Percentage (PEP) for the current insurance year is calculated by dividing the sum of $\mathrm{AE}$ for the insurance year, the change in Accounts Payable $(\triangle \mathrm{AP})$, and the change in Prepaid Expenses $(\triangle \mathrm{PE})$ (equation $\mathrm{A} 13)$. The values $\triangle \mathrm{AP}$ and $\triangle \mathrm{PE}$ provide oversight on the expense activity of the farm. Consideration of accrual adjustments ensures proper allocation of expenses to the year in which they are used to generate income. PEP is used to determine whether an adjustment to AAGR ensues (equations A13-A16).

When AAGR warrants adjustment, recalculation of AGR Loss Inception Point (AGRLIP) occurs by multiplying ADJAAGR by the elected CL (equation A17). Subsequently, AGRC for the insurance year (equation A18) is derived and then subtracted from the guarantee to determine if a revenue deficiency occurs for the farm (equation A19).

AGRC is calculated using AFI, $\triangle \mathrm{AR}, \Delta \mathrm{IN}$, Noninsured Disaster Assistance Payments (NAP), Net Gain from Commodity Hedging (NGCH), Gross Crop Insurance Indemnity Payments (GCIIP), Sugarbeet Payment-in-Kind
(SPIK), and Marketing Orders-cranberry and tart cherries (MO) (equation A18). NAP payments are excluded from AFI but included in AGRC. GCIIP are also included in determining AGRC for the current insurance year but excluded from AFI. These payments are included in AGRC as a preventative measure against "double-dipping," collecting for the same loss twice. Given that an individual sustained a revenue deficiency, an Indemnity (ID) is paid to the extent the payment rate allows, $75 \%$ or $90 \%$ of AAGR (equation A20).

\section{Premium Calculation}

To determine an overall net gain or loss from AGR-Lite, consideration must be given to the cost of the policy or premium. We evaluate AGR-Lite as a standalone product rather than a "wraparound" policy. AGR-Lite could be purchased to wrap around a standard Yield Protection (YP) policy to cover risks not insured by the YP policy. Furthermore, we assume annual enrollment each year over the entire study period. Following the procedure by Williams et al. (1993), the average premium rate (APR) is calculated by dividing total indemnities by total liabilities for all farms receiving at least one indemnity over the 12-year period and is equal to $2.62 \%$ (equation A21). The loss ratio for this group of farms is 1.0, whereas the loss ratio for the group of all farms is less than 1.0. The loss ratio is the total indemnity payments divided by total premiums for the period of time considered. This calculated percentage rate is then applied to each farm's liability each year to determine the theoretical premium charged in the study. This insurance rate is for the pool of insured. Few actuaries would argue the rate is always "fair" for the individual insured but only "fair" for the pool of those insured (those with similar risks).

Government subsidization, administrative fees, and catastrophic rate loading are not considered in the premium. Because this is a very short time period for any rate setting and with a lack of observed losses, it is unlikely any real rate would be set below this calculated proxy rate. The average premium rate charged by the Risk Management Agency (RMA) for all AGR-Lite 
policies sold in 2012 was $4.3 \%$ plus the administrative and operating expense reimbursement that is paid to the insurance provider (USDA, 2012b). Past RMA experience has demonstrated that a new product with limited data will often generate rates below the observed loss cost for the product. This is often true because of a moral hazard that was overlooked or adverse selection where only the riskier producers buy the coverage. This study demonstrates that some of the producers in the pool would not buy the coverage based on their historical experience and justifies why only farmers with an observed loss were included in the proxy rate. However, there is less concern that the rate is less than it should be in this case because the risk of a widespread catastrophic loss from farms, which include more than 50\% of their income from livestock, is less relative to crop farms. Feuz (2009) also concludes that AGR-Lite premiums are set too high relative to the risks that are insured. The average 2012 RMA rate of $4.3 \%$ is also used in addition to the $2.62 \%$ rate to determine its impact on preferences for using AGR-Lite.

\section{Data Limitations and Assumptions}

Provisions of the AGR-Lite contract specify certain agricultural program payments are included in the AGRA calculation, but not for AGRC and vice versa. Only payments received from Commodity Credit Corporation (CCC Loans), Sugarbeet (Payment-in-kind), and Marketing Orders are considered allowable income and accounted for when calculating AGRC. Lastly, Noninsured Crop Disaster Assistance Program payments (NAP) are not included in AGRA calculations but are included in AGRC. Although agricultural program payments are recorded in the KFMA data set, all proceeds are consolidated into one value. Therefore, NAP payments, Payment in Kind, Marketing orders, and CCC loans could not be isolated when deriving AFI or AGRC. Therefore, any agricultural program payments needed for calculating AGRA or AGRC are omitted.

As discussed previously, the AGR-Lite guarantee is based on the lesser of AGRA, IAGR, or EI from the annual farm report. Because the analysis uses historical data (1993-2010), it is not possible to determine EI for succeeding years. Therefore, EI was set equal to AGRA.

Breeding livestock depreciation is not recorded in the KFMA database, causing this expense to be excluded from the expense calculations. The AGR-Lite contract states that raised cull cows that are sold are included in AFI and AGRA. Alternatively, sales of cows and other capital assets (such as breeding livestock) are not included in AFI or AGRA. This presents an issue because the KFMA data do not allow the identification of corresponding costs (nor do most farm accounting systems) associated with livestock sales for any given year. Thus, sales of cows (breeding livestock) have been excluded from AGR-Lite calculations. Therefore, sales of livestock may not truly reflect income permitted by the policy.

Despite these limitations, the farm-level data used in this study from the KFMA database represent a substantial improvement over what has been used in previous analyses, which have primarily used budgeting and simulation methods and more closely represent what most farm managers will have in their records relative to other studies. The variety of net return patterns exhibited in the actual data can be difficult to simulate. Although farm managers will have information to complete the cash-based IRS Form 1040, Schedule F, many of them will have little if any data in accrual form on changes in accounts payable, accounts receivable, and inventories.

The analysis is completed under the following assumptions: first, that each farm qualifies for AGR-Lite coverage; second, each farm insures every year; and third, every farm selects the $75 \%$ coverage level and a $90 \%$ payment rate. This coverage level is the most common level selected by purchasers of AGR-Lite (USDA, 2012a). Purchasers of revenue products also often choose the highest price or payment rate; therefore, the $90 \%$ payment rate is used rather than $75 \%$. Premiums are used that allow comparison of risk reduction effectiveness of the program, excluding administrative costs, insurance firm profits, and subsidies. To measure the potential risk reduction from participation in AGR-Lite, means, standard deviations, 
minimums, and stochastic efficiency with respect to a function analysis are used to examine net farm income distributions with and without participation in AGR-Lite.

\section{Stochastic Efficiency with Respect to a Function}

According to Hardaker et al. (2004), stochastic efficiency with respect to a function (SERF) orders a set of risky alternatives in terms of certainty equivalents (CEs) for a specified risk preference. Strategies with higher CEs are preferred to those with lower CEs. The CE of a risky strategy is the amount of money at which the decision-maker is indifferent between the certain dollar value and the risky strategy. For a risk-averse decision-maker, the estimated CE is less than the expected value of the risky strategy.

The calculation of the CE depends on the utility function specified. Given a negative exponential utility function, which is used in this analysis, a specific absolute risk-aversion coefficient (ARAC) defined by Pratt (1964) as, $\mathrm{r}_{\mathrm{a}}(w)=-\mathrm{u}^{\prime \prime}(w) / \mathrm{u}^{\prime}(w)$, which represents the ratio of derivatives of the decision-maker's utility function, $\mathrm{u}(w)$, is used to derive CEs. Refer to Hardaker et al. (2004) for additional detail on the calculation of the CEs with a negative exponential utility function.

A negative exponential utility function used in the SERF analysis conforms to the hypothesis that managers prefer less risk to more given the same expected return. This functional form assumes managers have constant absolute riskaversion. Under this assumption, managers view a risky strategy for a specific level of riskaversion the same without regard for their level of wealth. Babcock, Choi, and Feinerman (1993) note that this functional form is often used to analyze farmers' decisions under risk. For additional justification for this functional form, refer to Schumann et al. (2004). Their work demonstrates that the negative exponential function can be used as a reasonable approximation of risk-averting behavior.

The net return data for each strategy is sorted into CDFs, which are used in the SERF analysis. A utility-weighted risk premium (RP), given risk-aversion, can be calculated using equation 1 once the strategies are ranked using the $\mathrm{CE}$ results. This is accomplished by subtracting the $\mathrm{CE}$ of a less preferred strategy (L) from the preferred strategy $(\mathrm{P})$.

$$
\mathrm{RP}_{\mathrm{P}, \mathrm{L}, \mathrm{r}_{\mathrm{a}}}=\mathrm{CE}_{\mathrm{P}, \mathrm{r}_{\mathrm{a}}(\mathrm{w})}-\mathrm{CE}_{\mathrm{L}, \mathrm{r}_{\mathrm{a}}(\mathrm{w})}
$$

The RP, a utility-weighted risk premium for a risk-averse decision-maker, reflects the minimum amount (\$/acre) that will have to be paid to a decision-maker to justify a switch from alternative P to L (Hardaker et al., 2004). As the degree of risk-aversion increases, the risk premium changes. When the risk premiums are positive in this analysis, AGR-Lite is preferred to no insurance. The range of ARAC values is reported for each farm where the RP is positive. These ARACs are compared with an upperbound ARAC for each farm based on a suggested upper bound by Anderson and Dillon (1992). They proposed a relative risk-aversion (RRAC) definition of 0.0 as risk-neutral and 4.0 as extremely risk-averse. Thus, as suggested by Hardaker et al. (2004), the upper range of an absolute risk-aversion ARAC for use with a negative exponential utility function is calculated by dividing 4.0 by an appropriate level of wealth. In this case, the measure of wealth is the 2010 whole-farm net worth for each respective farm used in the analysis (Langemeier, 2010). Simulation and Econometrics to Analyze Risk (SIMETAR ${ }^{\odot}$ ) developed by Richardson, Schumann and Feldman (2008) is used to conduct the SERF analysis.

\section{Results}

AGR-Lite is examined for its risk reduction potential using NFI distributions with and without AGR-Lite based on a premium with a loss ratio of 1.0 for those farms with indemnities, assuming a $75 \%$ coverage level and $90 \%$ payment rate. Fifteen of the 49 farms do not receive a single indemnity payment (Table 1). Fifteen farms receive one indemnity payment, whereas the remaining farms receive two to five payments during the 12-year analysis period. Average liabilities are highest for the single-payment farms. With an average premium rate of $2.62 \%$ applied to all farms, the 
Table 1. Summary by Frequency of Claim for 49 Southeast Kansas Beef Farms

\begin{tabular}{lccccr}
\hline $\begin{array}{l}\text { Years with } \\
\text { Indemnity }\end{array}$ & $\begin{array}{c}\text { Number of } \\
\text { Farms }\end{array}$ & $\begin{array}{c}\text { Average } \\
\text { Premium Paid }^{\mathrm{a}}\end{array}$ & $\begin{array}{c}\text { Average } \\
\text { Liability }^{\mathrm{b}}\end{array}$ & $\begin{array}{c}\text { Mean Standard } \\
\text { Deviation of } \\
\text { Liability }^{\mathrm{c}}\end{array}$ & $\begin{array}{c}\text { Average } \\
\text { Indemnity/ } \\
\text { Farm/Year }^{\mathrm{d}}\end{array}$ \\
\hline 0 & 15 & $\$ 4,409$ & $\$ 168,486$ & $\$ 42,979$ & $\$ 0$ \\
1 & 15 & $\$ 5,247$ & $\$ 200,518$ & $\$ 30,810$ & $\$ 26,208$ \\
2 & 11 & $\$ 3,239$ & $\$ 123,759$ & $\$ 26,764$ & $\$ 27,932$ \\
3 & 4 & $\$ 2,663$ & $\$ 101,757$ & $\$ 13,424$ & $\$ 22,183$ \\
4 & 1 & $\$ 3,457$ & $\$ 132,121$ & $\$ 27,938$ & $\$ 22,419$ \\
$5^{\mathrm{e}}$ & 3 & $\$ 1,934$ & $\$ 73,913$ & $\$ 20,734$ & $\$ 16,498$ \\
\hline
\end{tabular}

${ }^{a}$ Average premium paid by farm for each frequency of indemnity group based on a premium rate of $2.62 \%$ for all farms.

${ }^{\mathrm{b}}$ Average liability was computed by averaging the liability across farms for each frequency of claim.

${ }^{\mathrm{c}}$ Mean standard deviation of liability was calculated by taking the average of the standard deviation of liability by farm.

${ }^{\mathrm{d}}$ Average indemnity per farm per year was calculated using the following formula: ([sum of indemnities]/[number of farms]/ years with indemnity).

${ }^{\mathrm{e}}$ No farms had more than five years with indemnity payments. Each farm was in the program 12 years.

average annual premium is $\$ 4090$ per farm with a range of $\$ 398-\$ 17,473$ per farm.

Summary characteristics of each of the farms' net farm income distribution are reported in Table 2. AGR-Lite reduces the mean and standard deviation of net farm income on average for the group, but not each individual farm. It also raises the average minimum and lowers the average maximum observations of the net income distribution for the entire group of farms.

The SERF analysis reveals that 21 farms do not prefer AGR-Lite under any level of risk aversion as indicated by NP in the first segment of column two of Table 2. Of the 21 farms, 15 do not receive a single indemnity payment and five others receive a single payment $(5,6,17$, 25, and 39). These single payments are not enough to cause their NFI with AGR-Lite for that year to be equal to or higher than without AGR-Lite. One farm (23) receives two indemnity payments, but again these payments are not enough to cause its NFI with AGR-Lite for the two years to be equal to or higher than without AGR-Lite. As a result, the cumulative distribution of NFI without AGR-Lite is always located completely to the right of the cumulative distribution of NFI with AGR-Lite for these 21 farms.

An upper-bound ARAC was calculated for each farm as described previously. A "yes" in the first segment of column 2 of Table 2 indicates the farm prefers AGR-Lite at an ARAC value less than the individual farm upper bound ARAC. A "no" indicates the farm prefers AGR-Lite at an ARAC above the upper bound ARAC. NP indicates the farm never prefers AGR-Lite at any level of risk aversion.

The SERF analysis indicates that 28 farms prefer AGR-Lite at some level of risk-aversion (Table 2, column 2, segment 1). Eleven of these 28 farms prefer AGR-Lite at all levels of riskaversion above 0.0. Of the remaining 17 farms, 5 farms (e.g., farm 2) prefer AGR-Lite between an ARAC of 0.0 and some positive upper value. The upper positive value occurs for the five farms because the minimum outcomes with AGR-lite are more negative or less positive than those without AGR-Lite but the indemnities raise the mean NFI for these farms. For the remaining 12 farms, the ARACs where AGRLite first becomes preferred are well above 0.0. As described previously, an upper-bound ARAC for each farm is also applied to these farms. For ten of the 12 farms in which the minimum ARAC for preferring AGR-Lite is greater than 0.0, the minimum ARAC for the farm is above the farm specific upper-bound ARAC. For example, farm 43 (Table 2) prefers AGR-Lite at ARACs of 0.0000152676 and above, but the upper-bound ARAC for this farm is less than this value. Therefore, only 18 farms prefer AGR-Lite at levels of risk-aversion at or below the specific farm's upper-bound ARAC.

Although the SERF procedure provides a more thorough analysis of the preference for 


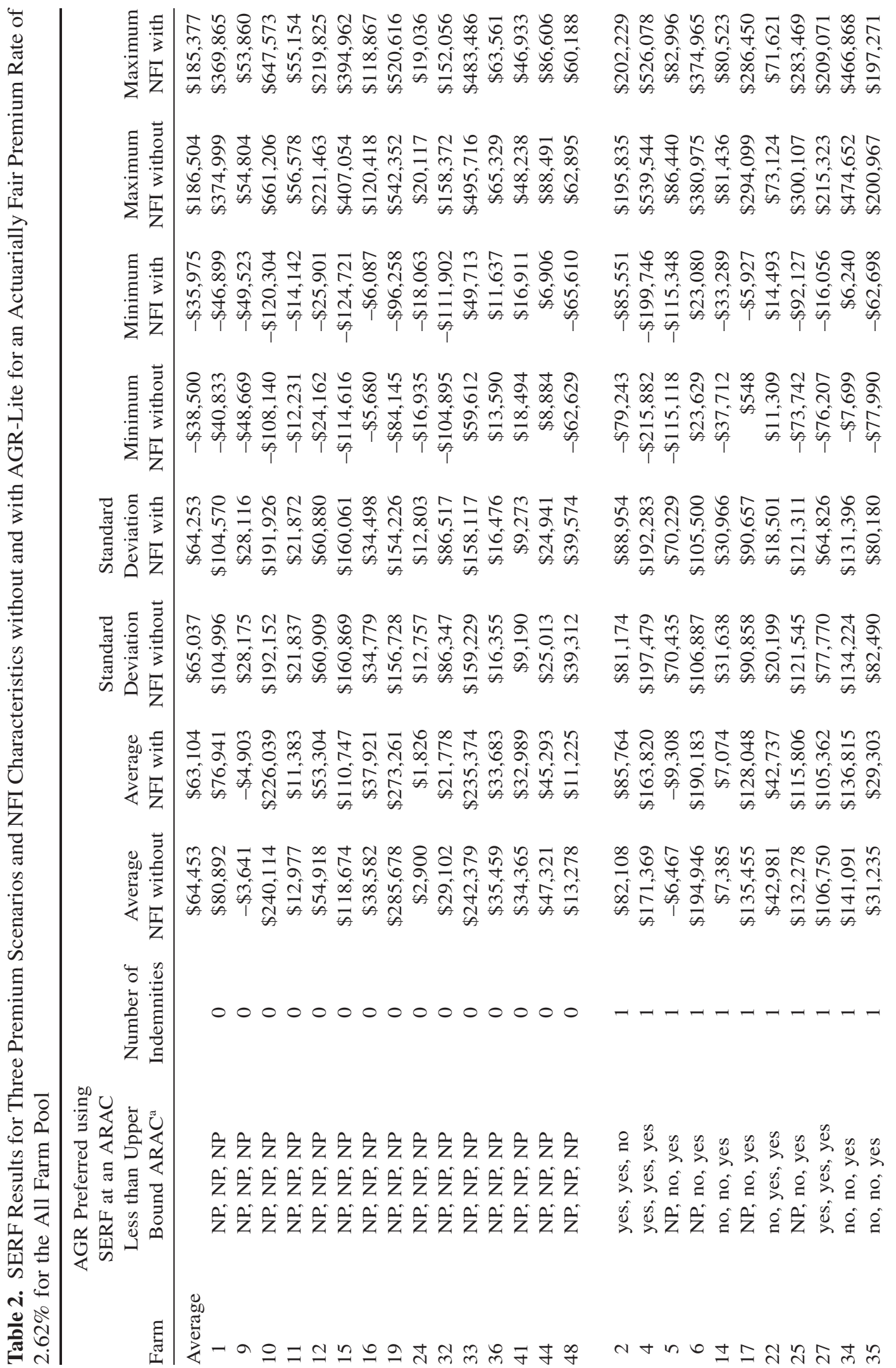




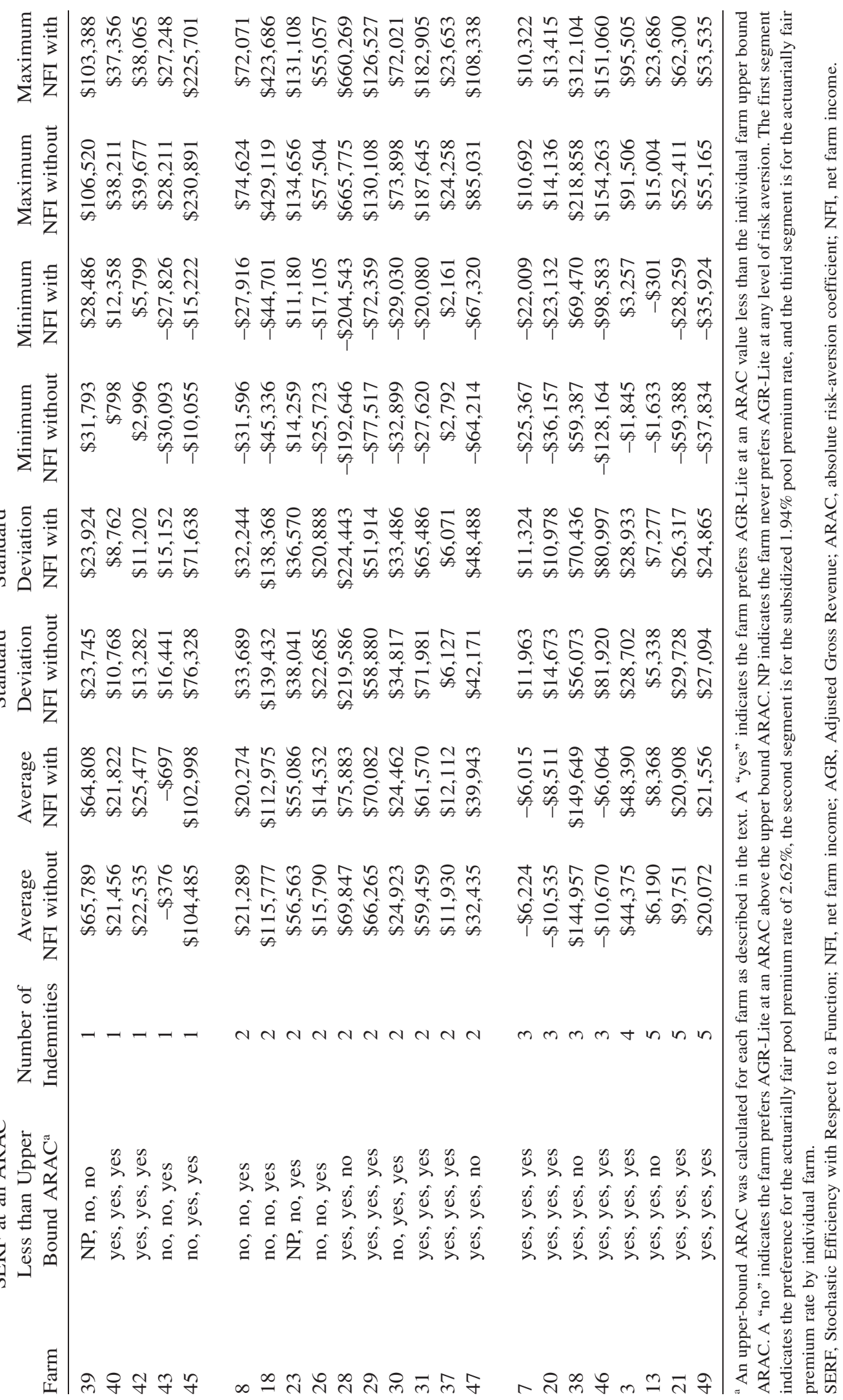


AGR-Lite by each individual farm, 11 of the 18 farms that prefer AGR-Lite with SERF have lower standard deviations and higher minimum observations of NFI. Ten farms have lower standard deviations, higher minimums, and lower maximums. Two of the 18 farms have a lower mean, standard deviation, maximum, and higher minimum NFI with AGR-Lite.

We also provide the results of SERF analysis for a subsidized premium rate of $1.94 \%$ for the pool of farms, which is the subsidized rate for all AGR-Lite contracts in 2012 (Table 2, column 2, segment 2). Three additional farms (22, 30, and 45) prefer AGR-Lite with this premium. Furthermore, additional SERF analysis results are provided for an actuarially fair premium by farm (Table 2, column 2, segment $3)$. In this case, premiums equal indemnities for each individual farm. Under this scenario, 15 farms that did not prefer AGR-Lite with the $2.62 \%$ pool premium rate now prefer AGRLite. However, five farms that preferred AGRLite under the $2.6 \%$ pool rate do not prefer AGR-Lite with the actuarially fair rate by farm. This resulted in 28 farms preferring AGR-Lite. This can be seen by comparing the information in Table 2, column 2, segments three and one.

Table 3 reports the results of the risk premium calculations for AGR-Lite under the $2.62 \%$ premium rate for the pool of farms. The farm-level ARACs used range from 0.0 (riskneutral) to 0.00003 (very risk-averse). The upper bound is the maximum ARAC calculated for each of the 49 farms described earlier. This insures that the upper bound is at least as large as the individual ARACs for all 49 farms.

The resulting risk premiums for the farms with no indemnities are all negative. In addition, the risk premiums are all negative for farms 5, 6, 17, 23, 25, and 39. Positive risk premiums indicate the farm manager prefers AGR-Lite at the specific ARAC. Farms 2, 4, 27, 40, 42, 28, 29, 31, 37, 47, 7, 20, 38, 46, 3, 13, 21, and 49 prefer AGR-Lite at an ARAC less than the upper-bound ARAC for the individual farm.

The trend in risk premiums for each individual farm can be compared, but risk premiums of different farms cannot. For example, farm two has a risk premium of $\$ 3656$ with risk-neutrality and prefers AGR-Lite up to an ARAC of 0.00000585 , but at higher ARACs does not prefer AGR-Lite, as demonstrated by a risk premium of $-\$ 2317$ at an ARAC of 0.00001 (Table 2). The negative risk premium indicates the farm would need to be paid $\$ 2317$ or have a higher NFI by that amount to prefer AGR-Lite at the corresponding level of risk aversion. Farm 40 prefers AGR-Lite at all levels of risk aversion, as demonstrated by the increasing positive risk premiums at each level of risk aversion (Table 2). The positive risk premiums indicate the farm would need to have to have a lower NFI by those amounts at the respective ARACs to not prefer AGR-Lite. As risk aversion increases, the preference for AGR-Lite increases. For the 18 farms that prefer AGR-Lite at some level of risk aversion below the farm's maximum ARAC, the risk premium increases as risk aversion increases for 12 farms. This indicates that their preference for the program increases as their risk aversion increases. The risk premium decreases as risk aversion increases for four farms and there is no trend in risk premiums for two farms that prefer AGR-Lite. For all nine farms that prefer AGR-Lite at a risk aversion level above the maximum ARAC for the respective farm, the risk premium increases as risk aversion increases. Each farm is a different size and has different amounts of acres, head of cattle, and other characteristics, so there is no way to standardize the risk premiums to a per-acre or per-head basis.

When the upper-bound ARACs for each farm are applied using a RRAC of 6.33, as suggested by Abdulkadri and Langemeier (2000), the number of farms included in the set preferring AGR-Lite increases from 18 to 19. When a RRAC of 12.0 is used, the set increases to 20. Therefore, the selection of the upperbound RRAC to calculate the ARAC has little effect on the results. Seven of the 11 that prefer AGR-Lite at all levels of risk-aversion have at least three indemnity payments during the 12-year period. In summary, the initial SERF analysis shows $37 \%$ of the farm managers prefer AGR-Lite.

The SERF analysis was repeated using net farm income distributions with a premium rate 
Table 3. AGR-Lite Risk Premiums ( $\$ /$ farm $)^{\mathrm{a}}$

\begin{tabular}{|c|c|c|c|c|c|}
\hline \multirow{2}{*}{$\begin{array}{l}\text { Number } \\
\text { of Indemnities }\end{array}$} & \multirow[b]{2}{*}{ Farm Number } & \multicolumn{4}{|c|}{ Absolute Risk Aversion Coefficients } \\
\hline & & 0.00000 & 0.00001 & 0.00002 & 0.00003 \\
\hline 0 & 1 & $-\$ 3,951$ & $-\$ 3,932$ & $-\$ 4,316$ & $-\$ 4,819$ \\
\hline 0 & 9 & $-\$ 1,263$ & $-\$ 1,246$ & $-\$ 1,226$ & $-\$ 1,205$ \\
\hline 0 & 10 & $-\$ 14,075$ & $-\$ 12,931$ & $-\$ 12,251$ & $-\$ 12,172$ \\
\hline 0 & 11 & $-\$ 1,594$ & $-\$ 1,599$ & $-\$ 1,601$ & $-\$ 1,601$ \\
\hline 0 & 12 & $-\$ 1,613$ & $-\$ 1,603$ & $-\$ 1,604$ & $-\$ 1,614$ \\
\hline 0 & 15 & $-\$ 7,927$ & $-\$ 8,010$ & $-\$ 8,770$ & $-\$ 9,279$ \\
\hline 0 & 16 & $-\$ 660$ & $-\$ 591$ & $-\$ 550$ & $-\$ 526$ \\
\hline 0 & 19 & $-\$ 12,417$ & $-\$ 11,587$ & $-\$ 12,067$ & $-\$ 12,110$ \\
\hline 0 & 24 & $-\$ 1,074$ & $-\$ 1,080$ & $-\$ 1,086$ & $-\$ 1,093$ \\
\hline 0 & 32 & $-\$ 7,324$ & $-\$ 7,404$ & $-\$ 7,386$ & $-\$ 7,321$ \\
\hline 0 & 33 & $-\$ 7,004$ & $-\$ 6,654$ & $-\$ 7,099$ & $-\$ 7,565$ \\
\hline 0 & 36 & $-\$ 1,777$ & $-\$ 1,795$ & $-\$ 1,815$ & $-\$ 1,835$ \\
\hline 0 & 41 & $-\$ 1,376$ & $-\$ 1,383$ & $-\$ 1,391$ & $-\$ 1,399$ \\
\hline 0 & 44 & $-\$ 2,028$ & $-\$ 2,011$ & $-\$ 1,995$ & $-\$ 1,981$ \\
\hline 0 & 48 & $-\$ 2,053$ & $-\$ 2,178$ & $-\$ 2,342$ & $-\$ 2,508$ \\
\hline 1 & 2 & $\$ 3,656$ & $-\$ 2,317$ & $-\$ 5,474$ & $-\$ 6,266$ \\
\hline 1 & 4 & $-\$ 7,549$ & $\$ 8,738$ & $\$ 15,315$ & $\$ 16,048$ \\
\hline 1 & 5 & $-\$ 2,841$ & $-\$ 2,640$ & $-\$ 2,384$ & $-\$ 2,175$ \\
\hline 1 & 6 & $-\$ 4,763$ & $-\$ 3,363$ & $-\$ 2,358$ & $-\$ 1,765$ \\
\hline 1 & 14 & $-\$ 311$ & $-\$ 102$ & $\$ 135$ & $\$ 399$ \\
\hline 1 & 17 & $-\$ 7,407$ & $-\$ 7,275$ & $-\$ 7,169$ & $-\$ 7,073$ \\
\hline 1 & 22 & $-\$ 244$ & $\$ 74$ & $\$ 418$ & $\$ 775$ \\
\hline 1 & 25 & $-\$ 16,472$ & $-\$ 16,873$ & $-\$ 17,655$ & $-\$ 18,044$ \\
\hline 1 & 27 & $-\$ 1,388$ & $\$ 13,029$ & $\$ 34,293$ & $\$ 48,956$ \\
\hline 1 & 34 & $-\$ 4,276$ & $-\$ 1,283$ & $\$ 1,539$ & $\$ 4,119$ \\
\hline 1 & 35 & $-\$ 1,932$ & $-\$ 5$ & $\$ 2,216$ & $\$ 4,658$ \\
\hline 1 & 39 & $-\$ 981$ & $-\$ 1,067$ & $-\$ 1,235$ & $-\$ 1,456$ \\
\hline 1 & 40 & $\$ 366$ & $\$ 553$ & $\$ 754$ & $\$ 970$ \\
\hline 1 & 42 & $\$ 2,942$ & $\$ 3,164$ & $\$ 3,359$ & $\$ 3,521$ \\
\hline 1 & 43 & $-\$ 321$ & $-\$ 119$ & $\$ 113$ & $\$ 368$ \\
\hline 1 & 45 & $-\$ 1,487$ & $\$ 1,615$ & $\$ 3,428$ & $\$ 3,602$ \\
\hline 2 & 8 & $-\$ 1,015$ & $-\$ 530$ & $\$ 20$ & $\$ 576$ \\
\hline 2 & 18 & $-\$ 2,802$ & $-\$ 2,046$ & $-\$ 1,670$ & $-\$ 1,308$ \\
\hline 2 & 23 & $-\$ 1,477$ & $-\$ 1,010$ & $-\$ 645$ & $-\$ 396$ \\
\hline 2 & 26 & $-\$ 1,258$ & $-\$ 860$ & $-\$ 385$ & $\$ 158$ \\
\hline 2 & 28 & $\$ 6,036$ & $-\$ 4,499$ & $-\$ 9,704$ & $-\$ 11,390$ \\
\hline 2 & 29 & $\$ 3,817$ & $\$ 7,244$ & $\$ 8,408$ & $\$ 7,340$ \\
\hline 2 & 30 & $-\$ 462$ & $-\$ 52$ & $\$ 307$ & $\$ 583$ \\
\hline 2 & 31 & $\$ 2,111$ & $\$ 5,526$ & $\$ 7,303$ & $\$ 7,975$ \\
\hline 2 & 37 & $\$ 182$ & $\$ 184$ & $\$ 184$ & $\$ 182$ \\
\hline 2 & 47 & $\$ 7,508$ & $\$ 4,543$ & $\$ 1,402$ & $-\$ 943$ \\
\hline 3 & 7 & $\$ 209$ & $\$ 278$ & $\$ 350$ & $\$ 423$ \\
\hline 3 & 20 & $\$ 2,024$ & $\$ 2,475$ & $\$ 2,955$ & $\$ 3,459$ \\
\hline 3 & 38 & $\$ 4,692$ & $\$ 189$ & $-\$ 48$ & $\$ 905$ \\
\hline 3 & 46 & $\$ 4,607$ & $\$ 5,865$ & $\$ 8,756$ & $\$ 12,630$ \\
\hline 4 & 3 & $\$ 4,016$ & $\$ 4,037$ & $\$ 4,208$ & $\$ 4,482$ \\
\hline
\end{tabular}


Table 3. Continued

\begin{tabular}{lcrrrr}
\hline \multirow{2}{*}{$\begin{array}{l}\text { Number } \\
\text { of Indemnities }\end{array}$} & Farm Number & 0.00000 & 0.00001 & 0.00002 & 0.00003 \\
\cline { 3 - 6 } & 13 & $\$ 2,178$ & $\$ 2,069$ & $\$ 1,967$ & $\$ 1,870$ \\
5 & 21 & $\$ 11,157$ & $\$ 12,406$ & $\$ 14,421$ & $\$ 17,040$ \\
5 & 49 & $\$ 1,484$ & $\$ 2,014$ & $\$ 2,487$ & $\$ 2,825$ \\
\hline
\end{tabular}

${ }^{\mathrm{a}}$ Risk premiums cannot be compared across farms because they are of different sizes and different characteristics.

of $4.3 \%$, the average unsubsidized rate of all AGR-lite polices purchased in 2012. Under this rate, only 12 farms (24.5\%) prefer AGR-Lite at levels of risk-aversion at or below the specific farm's upper-bound ARAC, or six farms less than the 18 that prefer the plan under the lower premium rate (results not reported in the article).

\section{Summary and Conclusions}

A panel data set of actual farm-level income data and cost was compiled to evaluate the impact of AGR-Lite on NFI variability for 49 southeast Kansas beef farms. Although actual income tax records were not available, annual data for the period 1993-2010 from the KFMA were used to reproduce the essential information from IRS Form 1040, Schedule F and inventory records that a farm manager would need to purchase AGR-Lite (Langemeier, 2010). Five years of historical data were required to perform the necessary calculations for the revenue guarantee and to purchase AGR-Lite each year. The data set allowed calculation of the impact of the whole-farm revenue insurance for the 12 years from 1999-2010 in contrast to previous research, which used simulation methods to generate whole-farm returns.

Net farm income distributions for each farm over this period were calculated for two strategies: either the farm manager insured or did not insure each year using AGR-Lite as a standalone product using a premium rate with a loss ratio of 1.0 for farms with indemnities. Although farm managers could enroll in alternative insurance products each year and the farm-level data did contain premium and indemnity payments, the data did not contain enough detail to identify which products these farms purchased. Necessary adjustments were made to examine the impact of purchasing AGR-Lite as a standalone product.

Income distributions of 12 observations for each strategy were calculated. The AGR-Lite analysis assumed a $75 \%$ coverage level and $90 \%$ payment rate. Statistics indicating the effectiveness of AGR-Lite at reducing net farm income risk include changes in NFI, standard deviation, and minimum outcomes. Stochastic Efficiency with Respect to a Function was also used.

Participation in AGR-Lite raised the NFI of 16 of the 34 farms receiving at least one indemnity payment and reduced the standard deviation of NFI on 27 of these 34 farms. It raised the minimum net farm income of 23 of the 34 farms. SERF results indicated that $37 \%$ of the farm managers preferred AGR-Lite. These results indicate that from a purely economic standpoint, the policy may have tangible benefits for some beef producers.

However, this examination of AGR-lite also reveals some additional issues. Excluding indemnity payments in calculating AGRA but including them in AGRC raises concerns that the product fails to address multiple-year losses. The revenue guarantee will decline in future years if indemnity payments are received but not included in AGRA, which effectively reduces the level of guarantee offered by AGRLite. Excluding indemnity payments from AGRC seems logical because it prevents managers from collecting for the same loss twice. Alternatively, including indemnity payments in AGRA and AGRC may be of some assistance to managers experiencing multiple-year losses.

The AGR-Lite policy includes cull cow sales in AGRA and AGRC. However, if cows are sold as part of herd reduction (not technically culls), any receipts from these sales are excluded from AGRC. This raises a question: 
what is the criterion for determining the difference between cull-cow sales and herd reduction resulting from poor pasture or feed availability resulting from drought? This was a very real issue in 2011 and 2012 with the large and severe drought in the southern Great Plains.

Purchased feed causes concern specifically for livestock producers. In years of drought or unfavorable yields, producers will likely purchase feed from external sources. Such purchases will not affect the calculation of AGRC, which is used to determine the indemnity. However, they will result in a reduction to net income. Therefore, the manager will effectively not be covered for such losses. Furthermore, farms that purchase feed will not find AGR-Lite attractive. If they sold all of their crop production and repurchased feed as needed, the crop sales will be in gross income and in poor crop years would be reflected in a lower gross income for AGRC. Unless the sale of the feed crops and repurchase are "arm's length transactions," this could increase moral hazard. A manager could create two separate corporations: one for crop enterprises and the other for livestock. In fact, this would be the best way to insure under AGR-Lite because it would remove all crops from the "farm" insured with AGR-Lite. The "crop farm" would retain any crop insurance program indemnities and these would not be included in the AGR-Lite calculations. The cattle sales calculation should be changed to cattle sales less feed costs. This would then provide more protection to those farms that purchase feed. However, in practice, each farm corporation would need to wait five years to accumulate the required (separate) income tax records to enroll in AGR-Lite. Enrollment in AGR-Lite is by individual taxable entity (USDA, 2007). This could be a significant hurdle, which would at least delay enrollment.

Despite AGR-Lite being touted as easy to understand, as a result of its design, this research highlights its inherent complexity, which may partially explain the relatively small use of the policy by producers. Proponents contend that given the use of IRS Form 1040, Schedule F, minimal additional recordkeeping is required. However, as presented in this study, thorough records including accrual-based accounting of inventories, accounts receivables, prepaid expenses, and accounts payable in addition to a cash-based Schedule F must be maintained for filing purposes. Few farms may have the additional data not required for Schedule F. In addition, Schedule C corporation tax returns contain less farm expense detail than the Schedule $\mathrm{F}$, thus requiring additional records. AGR-Lite is also more likely to increase the administrative cost for both RMA and the insurance provider. The complexity will require more insurance agent time to "educate" the producer on the product and to help the producer identify the information needed for purchase. The farm manager's cost may increase if an accountant is needed to prepare the data for the insurance application. Effectively AGRLite requires an accountant for loss-adjusting rather than a traditional crop production lossadjuster. This research draws attention to potential problem areas in addition to existing concerns with purchased feed, exclusion of indemnity payments, and breeding livestock.

Certain components of this policy have the potential to establish AGR-Lite as an effective risk management mechanism because it provides some income protection for the entire farm. The findings of this study indicate that risk reduction occurs on many of the beef farms. However, managers must consider that factors that lead to increased variability in NFI but not gross income (which the policy covers) ultimately limit the effectiveness of AGR-Lite as a risk management tool. Therefore, AGRLite may not be a viable risk management solution for some farm managers. This factor as well as the inherent complexity of the policy may explain why few policies have been sold in Kansas or nationally, despite the fact that it does provide discernible risk-mitigation and would be preferred by some producers based on the results of this study.

[Received March 2013; Accepted November 2013.]

\section{References}

Abdulkadri, A.O., and M.R. Langemeier. "Using Farm Consumption Data to Estimate the Intertemporal Elasticity of Substitution and 
Relative Risk Aversion Coefficients." Agricultural Finance Review 60(2000):61-70.

Anderson, J.R., and J.L. Dillon. Risk Analysis in Dryland Farming Systems. Rome, Italy: FAO, 1992. Atwood, A.J., M.J. Watts, and A.E. Baquet. "An Examination of the Effects of Price Supports and Federal Crop Insurance upon the Economic Growth, Capital Structure, and Financial Survival of Wheat Growers in the Northern High Plains." American Journal of Agricultural Economics 78,1(1996):212-24.

Babcock, B.A., E.K. Choi, and E. Feinerman. "Risk and Probability Premiums for CARA Utility Functions." Journal of Agricultural and Resource Economics 18,1(1993):17-24.

Barham, E.H.B., J.R.C. Robinson, J.W. Richardson, and M.E. Rister. "Mitigating Cotton Revenue Risk through Irrigation, Insurance, and Hedging." Journal of Agricultural and Applied Economics 43,4(2011):529-40.

Carriker, J.G., J.R. Williams, G.A. Barnaby, and J.R. Black. "Yield and Income Risk Reduction under Alternative Crop Insurance and Disaster Assistance Designs." Journal of Agricultural and Resource Economics 16,2(1991):238-50.

Dismukes, R., and K. Coble. "Managing Risk with Revenue Insurance. Washington, DC: U.S. Department of Agriculture Economic Research Service." Amber Waves 4,6(2006):22-27.

Dismukes, R., and R. Durst. Whole-farm Approaches to a Safety Net. Washington, DC: U.S. Department of Agriculture Economic Research Service Economic Information Bulletin EIB$15,2006$.

Feuz, D.M. "A Comparison of the Effectiveness of Using Futures, Options, LRP Insurance, or AGR-Lite Insurance to Manage Risk for Cow/ Calf Producers." NCCC-134 Conference Proceedings, 2009. Internet site: http://www.farmdoc. uiuc.edu/nccc134 (Accessed March 6, 2012).

Fields, D., and J. Gillespie. "Beef Producer Preferences and Purchase Decisions for Livestock Price Insurance." Journal of Agricultural and Applied Economics 40,3(2008):789-803.

Hardaker, J.B., J.W. Richardson, G. Lien, and K.D. Schumann. "Stochastic Efficiency Analysis with Risk Aversion Bounds: A Simplified Approach." The Australian Journal of Agricultural and Resource Economics 48(2004):253-70.

Langemeier, R.M. Kansas Farm Management SAS Data Bank Documentation. Kansas State University, Agricultural Exp. Sta., Agri. Economics Staff Paper No. 11-01. August 2010.

Llewelyn, V.R., J.R. Williams, B.W. Schurle, and M.R. Langemeier. "Analysis of FARRM and
Counter-cyclical Savings Accounts in Kansas.” Kansas State University, Agri. Exp. Sta. Rep. No. 03-408-A, 2003.

Miller, C., K.H. Coble, and B.J. Barnett. "Investigating the Implications of Multi-crop Revenue Insurance for Producer Risk Management." Paper presented at the Southern Agricultural Economics Association Meeting, Lexington, KY, January 29-February 2, 2000. Internet site: http://ageconsearch.umn.edu/bitstream/15802/ 1/pp00-002.pdf (Accessed February 16, 2012).

Miranda, J.M. "Area-Yield Crop Insurance Reconsidered." American Journal of Agricultural Economics 73,2(1991):233-42.

Mishra, A.K., and B.K. Goodwin. "Revenue Insurance Purchase Decisions of Farmers." Applied Economics 38(2006):149-59.

Patrick, G.F., and A.S. Rao. "Crop Insurance's Role in Risk Management on Hog-Crop Farms." North Central Journal of Agricultural Economics 11,1(1989):1-10.

Pratt, J.W. "Risk Aversion in the Small and in the Large." Econometrica 32, 1-2(1964):122-36.

Richardson, J.W., K.D. Schumann, and P. A. Feldman. "SIMETAR ${ }^{\odot}$. Simulation for Excel to Analyze Risk." Agricultural and Food Policy Center, Dept. of Agric. Econ., Texas A\&M University, 2008.

Richardson, J.W., E.G. Smith, and R.D. Knutson. "An Analysis of Whole-farm Revenue Safety Net Options in Agriculture." Working Paper, Agri. and Food Policy Center, Texas A\&M University, 2001. Internet site: http://ageconsearch. umn.edu/bitstream/42728/2/wp01-9.pdf (Accessed February 16, 2012).

Schnitkey, G.D., B.J. Sherrick, and S.H. Irwin. "Evaluation of Risk Reductions Associated with Multi-Peril Crop Insurance Products.” Agricultural Finance Review 63(2003):1-21.

Schumann, K.D., P.A. Feldman, J.W. Richardson, and E.G. Smith. "Comparisons of Alternative Safety Net Programs for the 2000 Farm Bill." Working Paper, Agri. and Food Policy Center, Dept. of Agri. Econ., Texas A\&M University, 2001. Internet site: http://www.afpc.tamu.edu/ pubs/0/232/wp01-3.pdf (Accessed February 16, 2012).

Schumann, K.D., J.W. Richardson, G. Lien, and J.B. Hardaker. "Stochastic Efficiency Analysis Using Multiple Utility Functions." Paper presented at the American Agricultural Economics Association Meeting, Denver, CO, August 1-4, 2004.

Stokes, J.R., W.I. Nayda, and B.C. English. "The Pricing of Revenue Assurance." American 
Journal of Agricultural Economics 79,2(1997): 439-51.

Turvey, C.G. "Whole-farm Income Insurance in a Canadian Context." Paper presented at the 2010 AAEA, CAES, and WAEA Joint Meeting, Denver, CO, July 25-27, 2010.

U.S. Department of Agriculture. Adjusted Gross Revenue Standards Handbook: 2007 and Succeeding Insurance Years. Washington, DC: Federal Crop Insurance Corporation: Product Administration and Standards Division FCIC18050-1, January 2007. Internet site: http:// www.rma.usda.gov/handbooks/18000/2007/ 07_18050.pdf (Accessed July 19, 2011).

Adjusted Gross Revenue-lite Standards Handbook: 2009 and Succeeding Insurance Years. Washington, DC: Federal Crop Insurance Corporation: Product Development Division, FCIC 18050-1, July 2008. Internet site: http:// www.rma.usda.gov/handbooks/20000/2009/ 20030.pdf.

2007 Census of Agriculture-Kansas State and County Data. 2009. Internet site: http://www.agcensus.usda.gov/Publications/2007/ Full_Report/.

Adjusted Gross Revenue-Lite. Washington,

DC: Risk Management Agency Program Aid
1907, 2010. Internet site: http://www.rma.usda. gov/pubs/rme/agr-lite.pdf.

. Summary of Business Application. Washington, DC: Risk Management Agency, 2012a. Internet site: http://www3.rma.usda.gov/ apps/sob/.

. Summary of Business. Washington, DC: Risk Management Agency, 2012b. Internet site: http:// www3.rma.usda.gov/apps/sob/insurancePlan. cfm (Accessed September 16, 2013).

Wang, H.H., S.D. Hanson, R.J. Meyers, and J.R. Black. “The Effects of Crop Yield Insurance Designs on Farmer Participation and Welfare." American Journal of Agricultural Economics 80,4(1998):806-20.

Williams, J.R., G.L. Carriker, G.A. Barnaby, and J.K. Harper. "Crop Insurance and Disaster Assistance Designs for Wheat and Grain Sorghum." American Journal of Agricultural Economics 75,2(1993):435-47.

Williams, J.R., A.T. Saffert, G. Art Barnaby, R.V. Llewelyn, and M.R. Langemeier. "Adjusted Gross Revenue-lite or Beef Farms Model Documentation." December 2013. Internet site: http://www.agmanager.info/crops/insurance/ workshops/filespdf/Appendix_JAAE.pdf (Accessed December 5, 2013). 